Open Access

\title{
Comparing solar photovoltaic and battery adoption in Ontario and Germany: an agent-based approach
}

\author{
Adedamola Adepetu ${ }^{1 \dagger}$, Ammar Alyousef $^{2 \dagger}$, Srinivasan Keshav ${ }^{1 *}$ (D) and Hermann de Meer ${ }^{2}$
}

\section{${ }^{*}$ Correspondence:}

keshav@uwaterloo.ca

${ }^{\dagger}$ Adedamola Adepetu and Ammar Alyousef contributed equally to this work.

${ }^{1}$ University of Waterloo, 200 University Avenue West, Waterloo, Canada

Full list of author information is available at the end of the article

\begin{abstract}
Background: We use Agent Based Models (ABMs) to study and contrast the projected adoption of integrated photovoltaic and battery systems in both Ontario, Canada and Bavaria, Germany.

Methods: We carry out surveys in both jurisdictions to elicit Agent Based Model (ABM) model parameters and to learn the decision function that determines whether an agent purchases a system or not. We use our fitted ABMs to assess the impact of different policy variants on Solar Photovoltaic (PV) system adoption in both jurisdictions.

Results: We find that different adoption behaviours exist in both jurisdictions, and that, in jurisdiction, of the polices that we considered, different policy incentives bring about the most significant increase in adoption. For example, reducing PV prices best increases adoption in Ontario but increasing the price of electricity would have the most significant impact in Germany.
\end{abstract}

Conclusion: ABMs allow policy makers and PV/battery manufacturers to estimate the jurisdiction-specific impact of a range of policy prescriptions.

Keywords: Agent-based modeling, Photovoltaic systems, Distributed generation, Energy storage

\section{Introduction}

Due to the threats posed by climate change, many jurisdictions around the world are striving to reduce their carbon footprint, for example, agreeing to the Paris Agreement sponsored by the United Nations ${ }^{1}$. Solar Photovoltaic (PV) systems, which have zero carbon emissions during operation, provide a viable alternative for energy generation. However, they produce no energy at night and highly variable energy during cloudy periods. PV systems can be combined with storage batteries to provide reliable power despite these limitations. As a result, integrated solar PV and battery ('PV-battery') systems represent an attractive alternative for low-carbon and sustainable energy generation.

Recognizing this fact, to encourage the use of solar and storage technologies, different incentives such as subsidies and Feed-in Tariff (FiT) contracts have been implemented in different parts of the world. Unfortunately, the same incentives have been met with varying degrees of success in different jurisdictions (Kazhamiaka et al. 2017). The goal of our work, therefore, is to compare outcomes from a set of plausible policies to determine

(c) The Author(s). 2018 Open Access This article is distributed under the terms of the Creative Commons Attribution 4.0 International License (http://creativecommons.org/licenses/by/4.0/), which permits unrestricted use, distribution, and reproduction in any medium, provided you give appropriate credit to the original author(s) and the source, provide a link to the Creative Commons license, and indicate if changes were made. 
the best policy incentive from this set that would promote the adoption of PV-battery systems in each jurisdiction. Specifically, we use jurisdiction-specific ABMs to study the different policy incentives that could bring about the greatest increase in adoption in each jurisdiction ${ }^{2}$.

We find that in Ontario, reducing PV prices significantly impacts adoption but in Germany, increasing the price of electricity would have the most significant impact.

The rest of this paper is structured as follows: In "Background" section, we present a background and literature review. We detail our methodology in "Methods" section. In "Ontario case study" and "Germany case study" sections, we use this methodology to study PV-storage adoption in Ontario and Germany, respectively. In "Comparison between Ontario and Germany case studies" section, we compare the findings of both case studies. Finally, in "Conclusions" section, we conclude and present policy implications.

\section{Background}

To encourage the use of solar and storage technologies, different incentives such as subsidies and FiT contracts have been implemented in different parts of the world. For example, the Renewable Energy Act (Ernewbare Energie Gesetz (EEG)) was passed in Germany in $2000^{3}$. Under this act, homeowners can purchase solar PV systems and sell the generated electricity back to the grid at a price that is guaranteed for 20 years (BNetzA 2015b). When it was introduced, the FiT price was much greater than the price of grid electricity, so all the generated renewable energy was fed into the grid to maximize the profit that it homeowners made on their investment.

Based on this significant government support, the renewable industry in Germany, particularly PV, grew rapidly between 2004 and 2012. The share of energy derived from renewable sources in Germany between 2004 and 2014 increased from 11.5 to 31\% - 6.8\% of this increase resulted from solar PV (Wirth and Schneider 2015). On sunny weekdays, electricity from PV systems sometimes meets up to $35 \%$ of the instantaneous electricity demand, rising to nearly 50\% on weekends and holidays (Wirth and Schneider 2015). Note that, although there was a high level of PV adoption in Germany between 2010 and 2012, the adoption rate has slowed down subsequently (BNetzA 2015a). This is probably a result of amendments to the EEG to reduce the FiT to the price that is below the price of grid electricity, making solar investments less profitable. Instead, the higher price of grid electricity incentivizes homeowners to install local storage and meet as much of their needs from local generation as possible. We investigate this trend further in this paper.

Like Germany, Ontario also has a 'microFiT' program targeted to homeowners and small businesses, with a maximum generating capacity of 10 KiloWatt (kW) (IESO 2015a; 2015b; 2016). Ontario also supports a 'net metering' program (not available in Germany), where a homeowner pays only for energy consumed net of local generation, and receives credits if the generation exceeds consumption (a relatively rare event). Despite these two programs, there has been a lower level of PV adoption in Ontario than in Germany. Specifically, at the start of 2016, only 23,061 solar PV microFiT contracts had been signed, in a population of approximately 4.9 million households (IESO 2016; Statistics Canada 2011). In this work, we seek to explain this difference in adoption using Agent-Based 
Models (described in "Methods" section), then use our insights to determine the best policies to encourage the adoption of PV-battery systems in both Ontario and Germany.

\section{Literature review}

We restrict our review of prior work to studies that have used ABMs or similar approaches to study the adoption of solar PV systems.

Using an ABM, Zhang et al. (2015; 2014) study PV adoption in San Diego, California, with a focus on two policies: PV price reduction and seeding PV purchase by giving systems to low-income households. The net present value of a system influences agents' decisions to purchase PV systems.

Zhao et al. (2011) combine ABMs and system dynamics to study PV adoption. The purchase decision is based on income, payback period, residence location, and advertisements. Also, a willingness-to-pay is used as a threshold for PV adoption. Simulating different scenarios, this study shows that PV adoption is better incentivized in smaller cities.

Robinson et al. (2013) conduct a household PV adoption case study on Austin, Texas. This is based on an ABM with Geographic Information Systems (GIS) features, where agent purchase decisions are defined using the Theory of Planned Behaviour (TPB) and social influence. Similarly, Palmer et al. conduct a case study on PV adoption by households in Italy. The agent purchase decision variables include the agent's income, care for the physical environment, payback period, and social influence; income has the most significant impact. This study has been extended by Rai et al. (2015), with a focus on rebate programs.

Iachini et al. (2015) study the social and economic factors that affect PV adoption. Similar to Palmer et al. (2015), the purchase decision is influenced by income, care for the physical environment, payback period, and social influence.

Murakami (2014) focuses on the social component of PV adoption. This study incorporates the capacity limits for PV-grid integration, based on grid stability. This study also considers the impact of using batteries in the grid but does not study battery adoption.

We improve on these studies by studying systems that incorporate both batteries and PV systems, rather than PV systems alone. In addition, we conduct case studies in both Ontario and Germany, rather than in a single jurisdiction.

\section{Methods}

We use ABMs for our study: the approach is summarized here and details can be found in (Adepetu 2016a). An ABM system comprises of agents that have certain properties and behaviours. Agents interact with one another and with their environment (Macal and North 2010); emergent system behaviour arises from the aggregation of their actions and interactions. It has been found that many energy policies can be studied using ABMs, regardless of the complexity of the policy (Van Dam et al. 2012; Nikolic and Ghorbani 2011).

To set up our ABM, we model homeowners as agents who are influenced by their social network when purchasing PV-battery systems (Kulviwat et al. 2009). We use Bass's (Bass 2004) categorization of adopters as innovators, early adopters, early majority, late majority, and laggards. Innovators tend to adopt new products without any social influence while laggards adopt commonplace products. We model this order of adoption 
in each agent using a social threshold $T$ where $0 \leq T \leq 1$ (Granovetter 1978) and the value is drawn from a truncated normal distribution. We use our model to compare emergent behaviour from agent decisions in response to a set of energy policies. Agent parameters are chosen based on data sources, as detailed in each case study.

We aim to model both rational and irrational factors that affect agent behaviour (i.e. purchasing PV-battery systems and consuming electricity). Purchasing PV-battery systems, in particular, can depend on rational factors such as a budget, payback period, system cost, and annual Return on Investment (RoI). Irrational factors include perceived impact of PV systems on the physical environment, concern for the physical environment, prior knowledge of PV systems, and susceptibility to social influence.

We validate our models by simulating historical adoption using the same system prices and market conditions that existed in the past. For each level of adoption in the population, we compare the predicted adoption to the actual adoption during the period being simulated. This is discussed in more detail in "Validation" section.

\section{Ontario case study}

In this section, we discuss the use of an ABM to study the adoption and usage of PVbattery systems in Ontario.

\section{Data}

We obtain electricity prices and PV-battery system prices from public sources (Ontario Energy Board 2015b; SunSmart Solar 2016) and vendor quotes ${ }^{4}$. Hourly electricity load data from the anonymized smart meter readings of 100 residences in Ontario, Canada were obtained from a utility company. We estimate PV electricity generation in Toronto, Ontario using the well-known System Advisor Model (SAM) ((Blair et al. 2014)). Environment variables that correspond to different policy scenarios are shown in Table $1^{5}$ and 2).

To determine agent parameters, we conducted a survey of Ontario residents, and asked them about their attitudes towards purchasing PV-battery systems. Specifically, we presented survey respondents with different options for PV-battery systems, with different system costs, payback periods, and return on investment and asked them if they would purchase such a system ${ }^{6}$. Figure 4 shows examples of options in the survey questions. We also gauged the respondent's level of concern for the physical environment.

We distributed the survey online using Crowdflower (Crowdflower Inc. 2017) to target Ontario residents. In an attempt to exclude poor-quality responses, we included questions to test the attentiveness of respondents and removed all responses from respondents who answered these questions incorrectly. We had 648 survey respondents from Ontario; 381 responses were valid.

\section{Feature selection and logistic regression}

To predict agent purchase decisions, we used ridge regression (Hoerl and Kennard 1970) ${ }^{8}$ 10 -fold cross validation to fit a decision function to the features describing the PV system. Based on the regression, the significant factors were found to be the payback, budget, whether or not the system included a battery, and system cost. Figure 5 shows the coefficients for each variable in all 10 fold scenarios. Other variables such as the RoI, 
Table 1 Environment Parameters (At the Time of the Study)

\begin{tabular}{|c|c|c|}
\hline Variable & Definition & Source \\
\hline FiT price $(\$ / k W h)$ & $\begin{array}{l}\text { Price for each unit of electricity } \\
\text { generated. }\end{array}$ & $\begin{array}{l}\text { The FiT price for rooftop PV systems smaller } \\
\text { than } 10 \mathrm{~kW} \text { in Ontario was } \$ 0.384 / \mathrm{kWh} \text { (IESO } \\
2015 \mathrm{a} \text { ) and in Germany was } € 0.125 / \mathrm{kWh} \text { (BNetzA } \\
2015 \mathrm{~b} \text { ). }\end{array}$ \\
\hline $\begin{array}{l}\text { Tou Electricity } \\
\text { Price }\end{array}$ & $\begin{array}{l}\text { Price of electricity depending on } \\
\text { the time of day, day of week, and } \\
\text { season. }\end{array}$ & $\begin{array}{l}\text { Figure } 1 \text { shows the ToU prices in Ontario }{ }^{7} \text {. } \\
\text { Germany does not have ToU prices: the price } \\
\text { of grid electricity is } € 0.295 / \mathrm{kWh} \text { (Eurostat 2016), } \\
\text { (Statista 2017) }\end{array}$ \\
\hline $\begin{array}{l}\text { Installed Solar PV } \\
\text { price }(\$ / \mathrm{kW})\end{array}$ & $\begin{array}{l}\text { Purchase and installation cost of PV } \\
\text { systems. }\end{array}$ & $\begin{array}{l}\text { Figure } 2 \text { (SunSmart Solar 2016) shows the price } \\
\text { per kW for different kW capacities in Ontario and } \\
\text { Fig. } 3 \text { shows the price for different PV capacities } \\
\text { in Germany(BDEW 2015b). }\end{array}$ \\
\hline $\begin{array}{l}\text { Installed Battery } \\
\text { Price }(\$ / \mathrm{kWh})\end{array}$ & $\begin{array}{l}\text { Purchase and installation cost of a } \\
\text { battery storage system. }\end{array}$ & $\begin{array}{l}\text { Given market trends, we use } \$ 1,500 / \mathrm{kWh} \text { in } \\
\text { Ontario (Shahan 2015) and } € 1000 / \mathrm{kWh} \text { in } \\
\text { Germany (Wirth and Schneider 2015) }\end{array}$ \\
\hline
\end{tabular}

concern for the environment, and prior knowledge of solar systems were found to be non-influential in the purchase decision.

Table 3 shows the logistic regression variables and coefficients. Purchasing the PVbattery system is labeled 0 and not purchasing the PV-battery system is labeled 1 . All the variables and the intercept fall within the desired 95\% confidence interval. The logistic regression model shows that as the payback period increases, an agent is less likely to make a purchase. Also, the higher an agent's budget, the higher the likelihood of a system purchase. These results are as expected.

\section{Agent behaviour}

Agents in our model can consume electricity, purchase PV and/or storage systems, and having done so, can generate electricity. We discuss these behaviours next.

We use an hourly model for electricity consumption, as described in "Data" section.

\section{PV-Battery purchase}

An agent considers buying a PV-battery system if it does not own a PV-battery system and its social threshold parameter exceeds the fraction of its social network that owns PV-battery systems. Algorithm 1 shows the purchase decision process.

The system options available are solar PV system capacities of 3, 6, and $9 \mathrm{~kW}$, each without and with batteries of 4 and 8 KiloWatt hour (kWh) capacity. From a list of possible system options that an agent is willing to purchase, one option is chosen randomly. This

Table 2 Battery Operation Parameters

\begin{tabular}{lll}
\hline Variable & Definition & Source \\
\hline $\begin{array}{l}\text { Battery Depth of } \\
\text { Discharge (DoD) }\end{array}$ & $\begin{array}{l}\text { Battery capacity proportion that can } \\
\text { be utilized. }\end{array}$ & $\begin{array}{l}\text { Current lithium ion (Li-ion) batteries have a DoD of } \\
\approx 80 \%(\text { Ghiassi-Farrokhfal et al. 2015), (Wang et al. } \\
2012) .\end{array}$ \\
$\begin{array}{ll}\text { Battery Life } \\
\text { (years) }\end{array}$ & $\begin{array}{l}\text { Length of time between a battery's } \\
\text { first use and its decommissioning. }\end{array}$ & $\begin{array}{l}\text { Based on typical values for current Li-ion batteries, } \\
\text { we choose a battery life of 10 years (Wang et al. } \\
\text { 2012) }\end{array}$ \\
$\begin{array}{ll}\text { Battery Charge } \\
\text { Efficiency (years) }\end{array}$ & $\begin{array}{l}\text { Percentage of charging energy that } \\
\text { is actually stored. }\end{array}$ & $\begin{array}{l}\text { Li-ion batteries have 85\% charge efficiency (Wang } \\
\text { et al. 2012). }\end{array}$ \\
Efficiency (years) & $\begin{array}{l}\text { Percentage of discharged energy } \\
\text { that is not lost as heat. }\end{array}$ & $\begin{array}{l}\text { Li-ion batteries have } \approx \text { 100\% discharge efficiency } \\
\text { (Wang et al. 2012). }\end{array}$ \\
\hline
\end{tabular}


Table 3 Logistic Regression Result (Ontario)

\begin{tabular}{lllll}
\hline Variable & Coefficient & Standard error & $z$ & $P>|z|$ \\
\hline Intercept & -1.0535 & 0.159 & -6.641 & 0.000 \\
Payback & 0.0945 & 0.009 & 10.265 & 0.000 \\
Battery & 0.3810 & 0.065 & 5.843 & 0.000 \\
PV Budget & -0.2142 & 0.020 & -10.774 & 0.000 \\
System Cost & $2.89 \mathrm{e}-05$ & $4.41 \mathrm{e}-06$ & 6.554 & 0.000
\end{tabular}

is because the survey shows that all the systems meet the purchase criterion, and there is no obvious way for us to rank one system over another.

\section{Electricity generation and storage operation}

If an agents purchases a PV system, they can operate it either using a FiT or a net metering contract. FiT contracts are attractive when the FiT rate is higher than the price of electricity, otherwise the agent uses a net metering contract. Agents use energy from the battery store, if possible, during the peak electricity price period while the battery is charged during other periods.

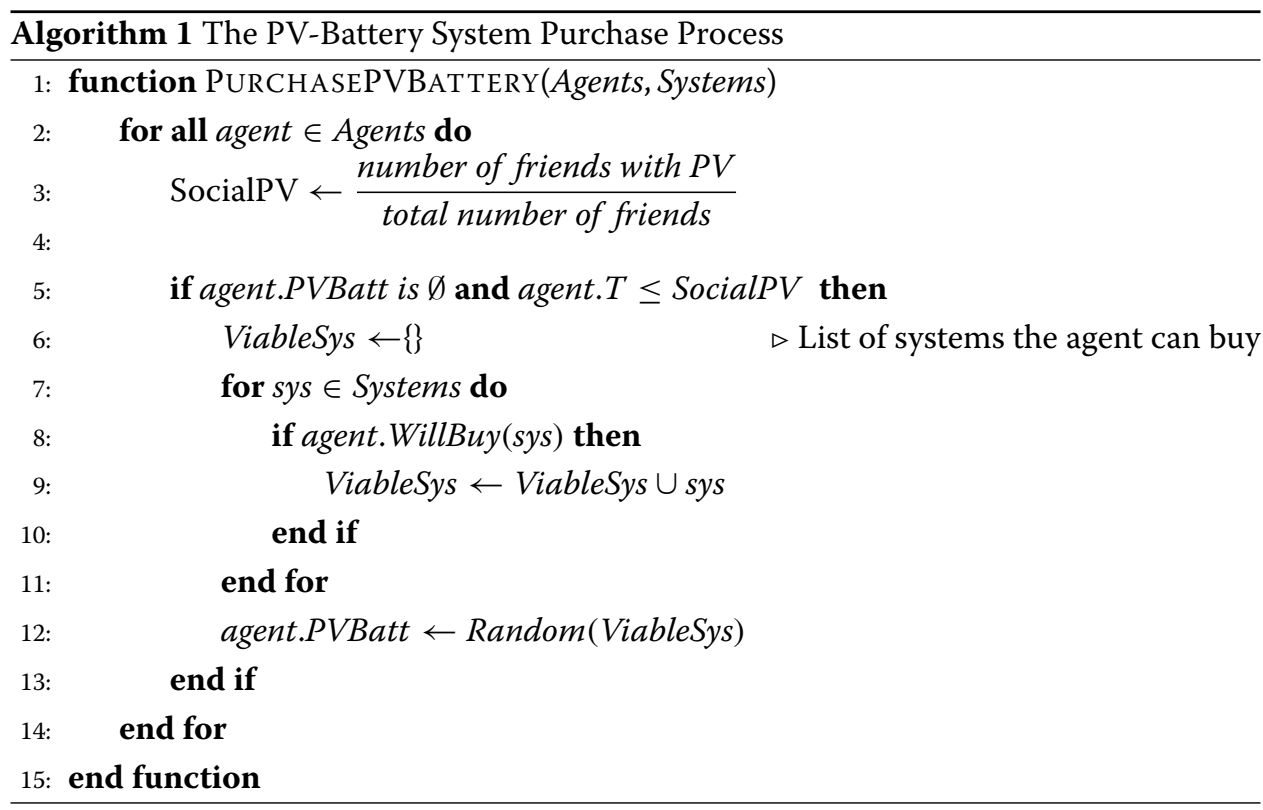

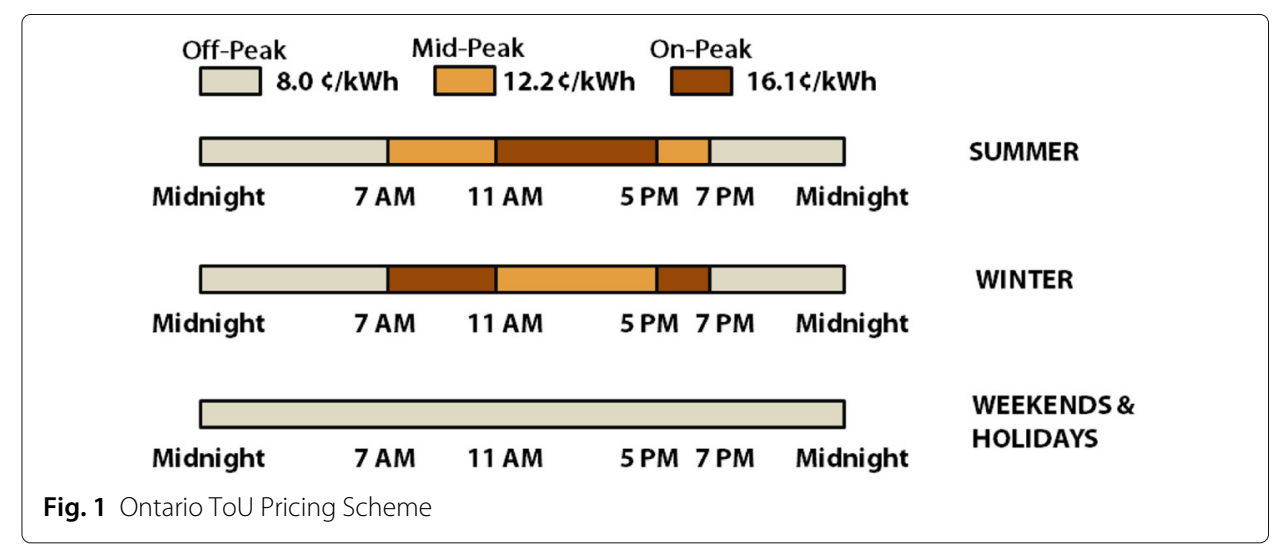




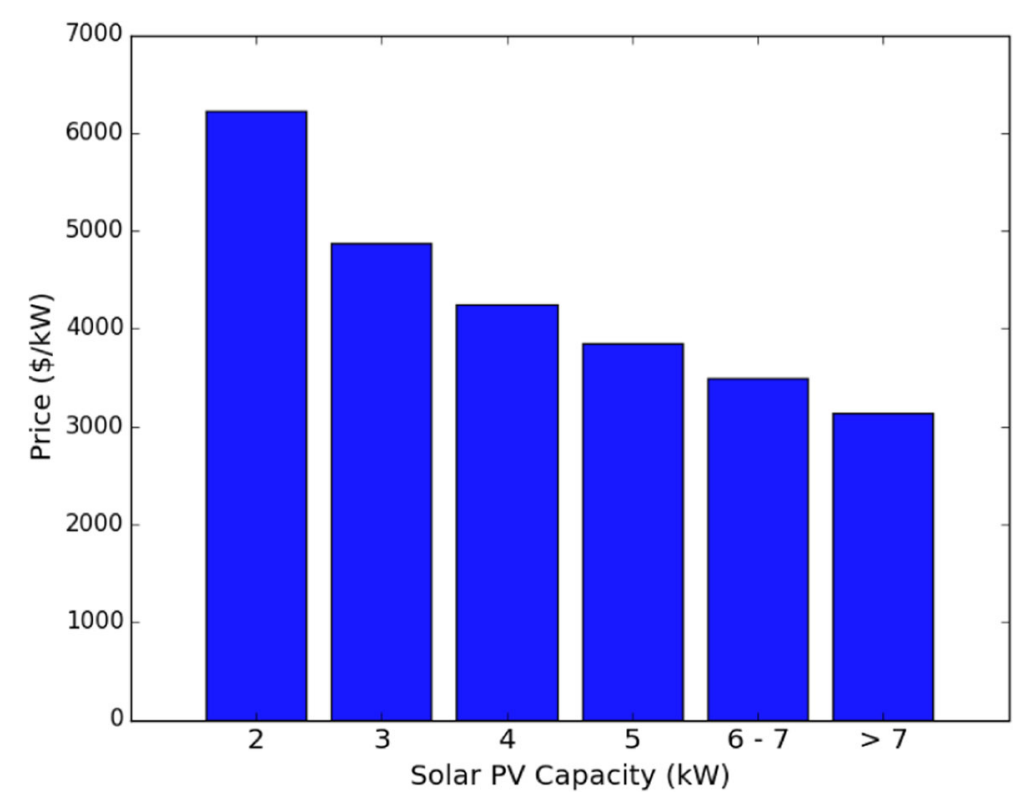

Fig. 2 Solar PV Prices in Ontario

\section{Validation}

The social threshold parameter for the $i^{\text {th }}$ agent, $T_{i}$, is assumed to be drawn from a truncated normal distribution. However, the mean and standard deviation of this distribution are free parameters. To discover the best values for these parameters, we simulate PV adoption for 26,160 agents between 2010 and 2014, each modeled using survey responses, for different values of these parameters and compare it with the actual FiT contract adoption for this period (IESO 2015b). The best FiT values of these parameters are then used in our simulations.

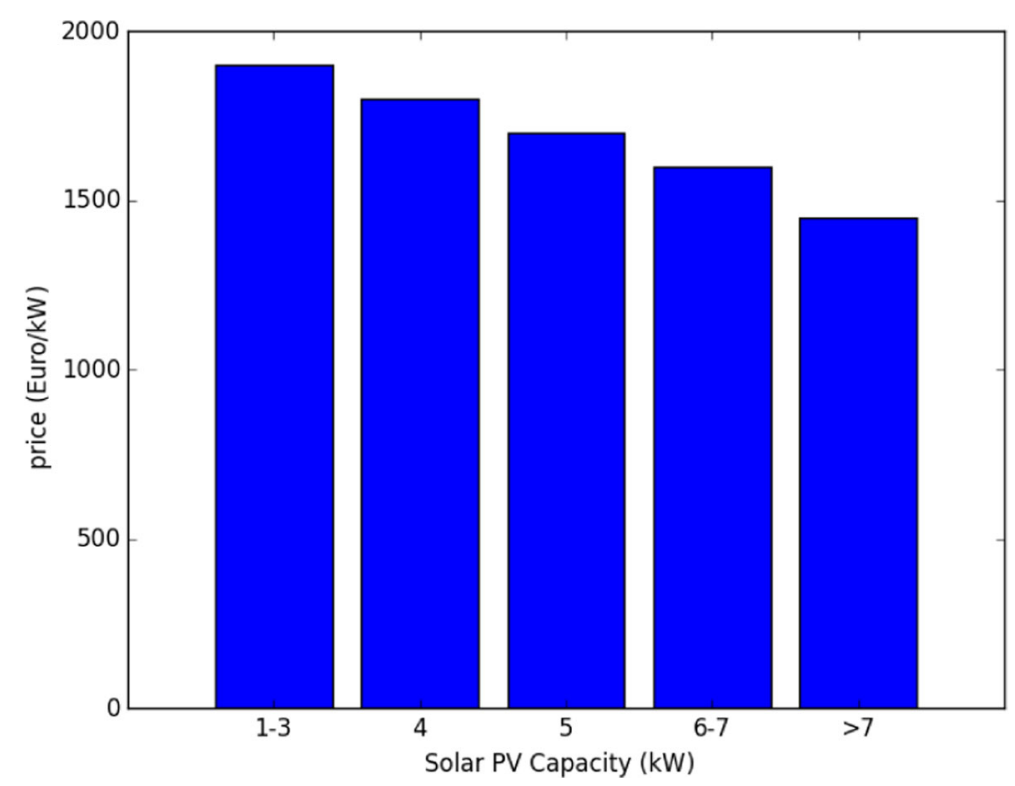

Fig. 3 Solar PV Prices in Germany 


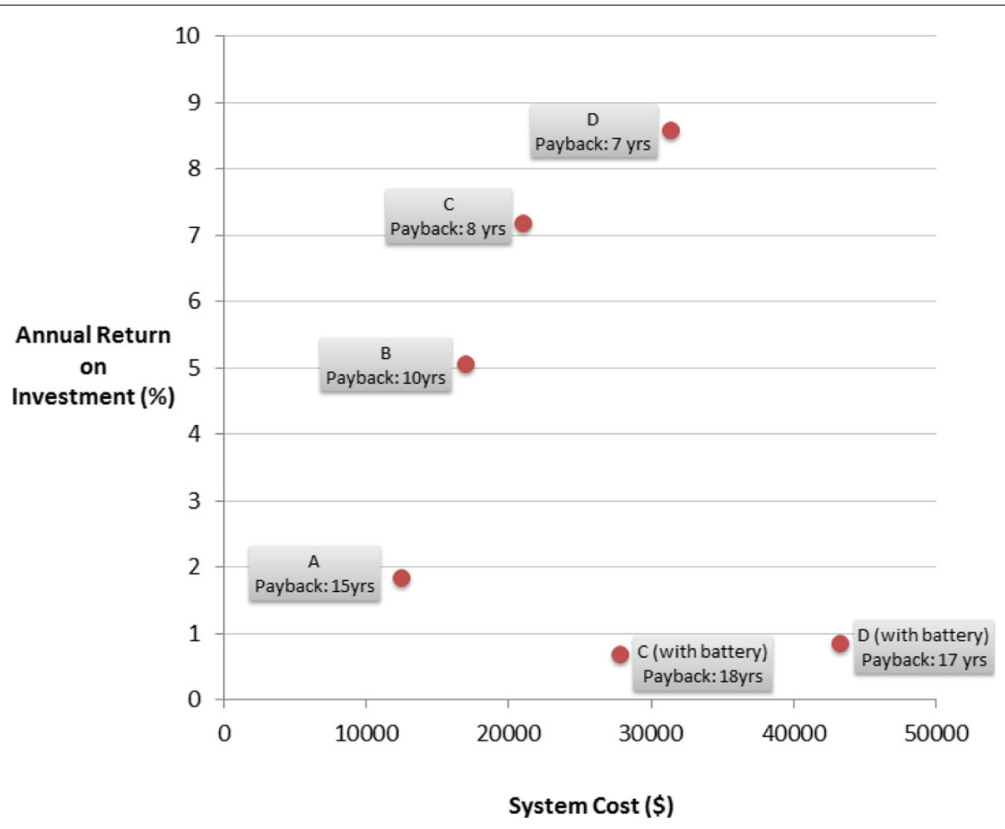

Fig. 4 Sample Survey Question: Which system(s) would you buy?

More specifically, in our simulations, the PV price, ToU electricity price, and FiT values were chosen based on historical price and FiT data (Fig. 6 (IESO 2015b; Ontario Energy Board 2015b; Feldman et al. 2014)). We executed 20 validation simulations for each mean $\mu$ and standard deviation $\sigma$ for the $T$ distribution. The distribution of prediction errors (in FiT adoption) can be seen in Figs. 7 and 8. We see that for the $T$ distribution parameters of $\mu=0.42$ and $\sigma=0.14$ (highlighted box in Fig. 7), we obtained the closest match and least error. The figure also compares the simulation results for these values and historical adoption, showing a visually good fit. Hence, we use $\mu=0.42$ and $\sigma=0.14$ for $T$ distributions to study the impact of various alternative policy prescriptions.

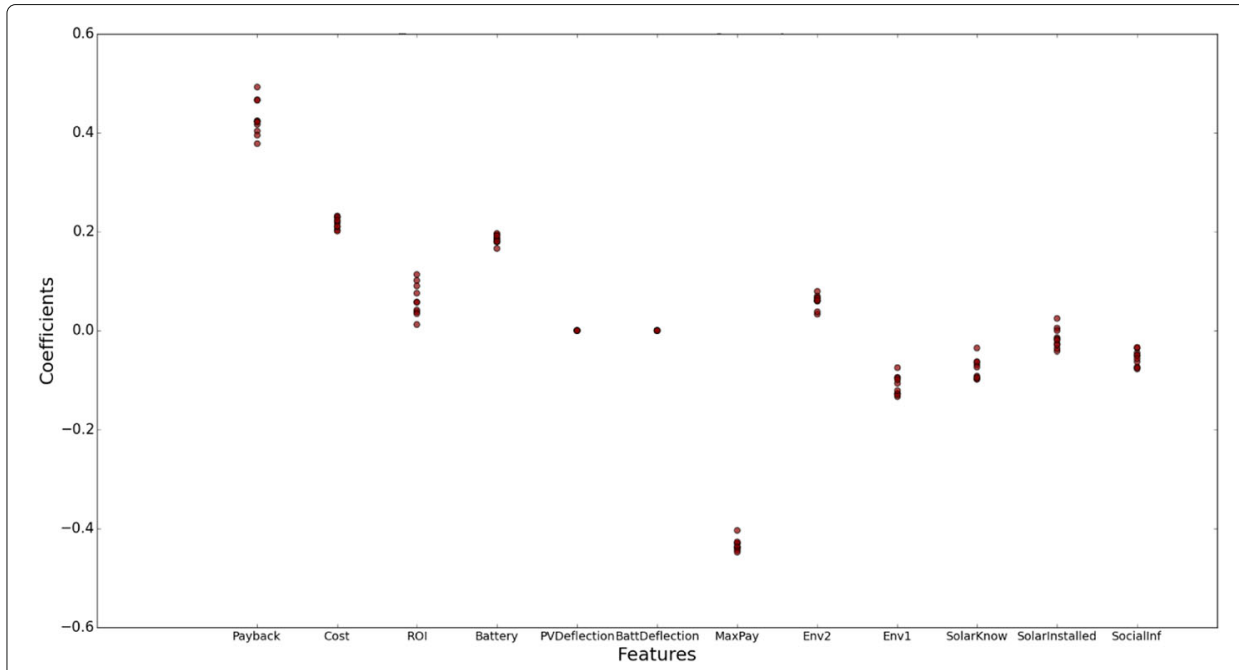

Fig. 5 Coefficients for Feature Selection using Ridge Regression (Ontario) 


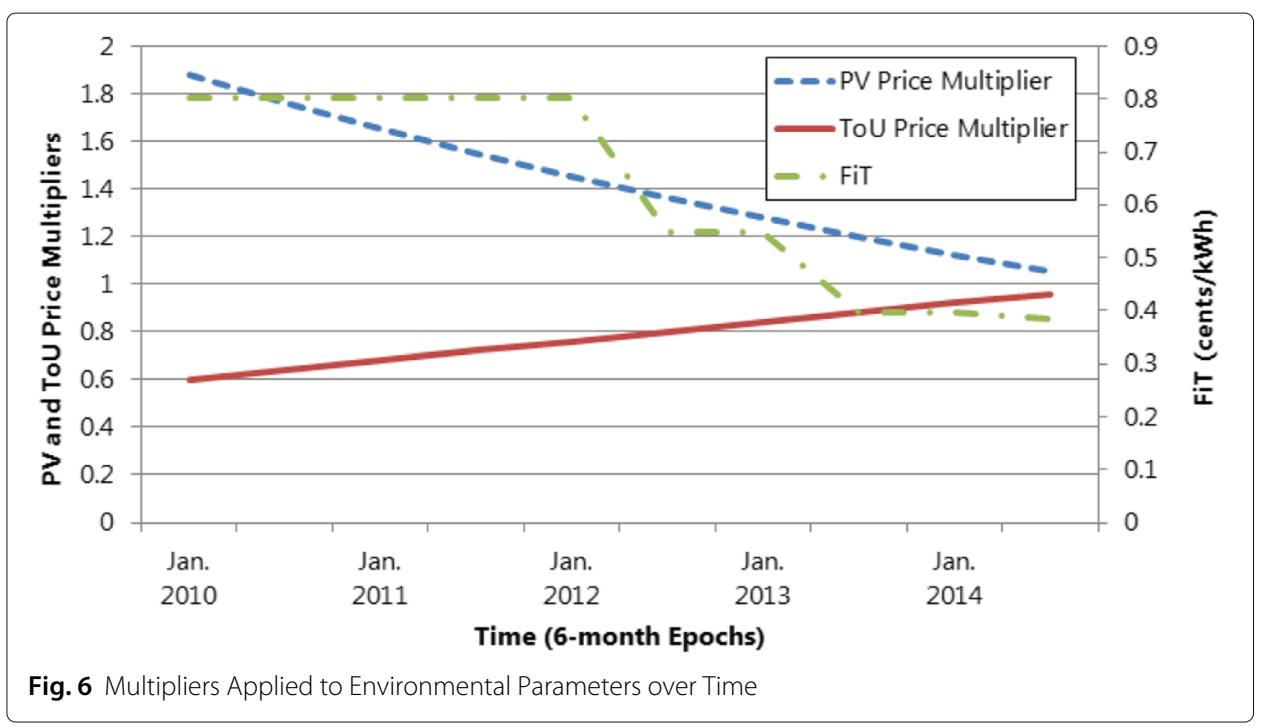

Simulation results

Policy parameters

We use ABM simulations to study the following potential policy prescriptions over a 10year simulation period:

- Base case: The system prices change based on current trends (Ontario Energy Board 2015b; Parkinson 2015). To model the historical decline in FiT prices in Ontario, we assume that the FiT price will continue to decrease linearly towards $0 \$ / \mathrm{kWh}$

- Less slow reduction in FiT, to continue to encourage solar adoption (compared to the base case)

- Increase in grid (ToU) electricity price by a ratio of 6:1 (compared to 2:1 in the base case)

- Reduced price of PV systems (compared to the base case)

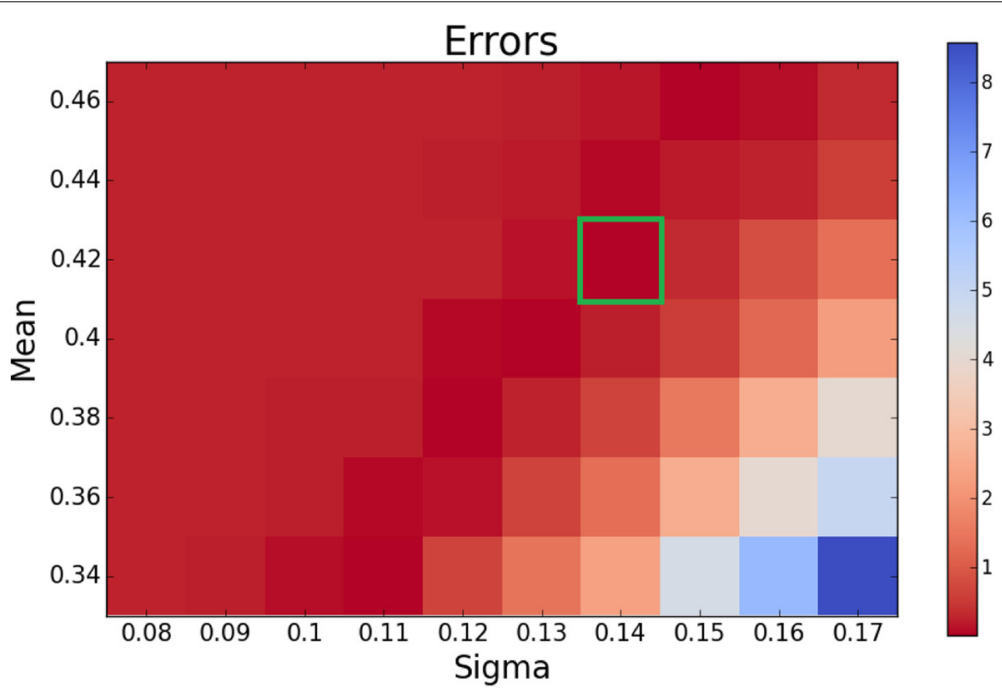

Fig. 7 RMSE for different values of the parameters of the social threshold distribution, Ontario 


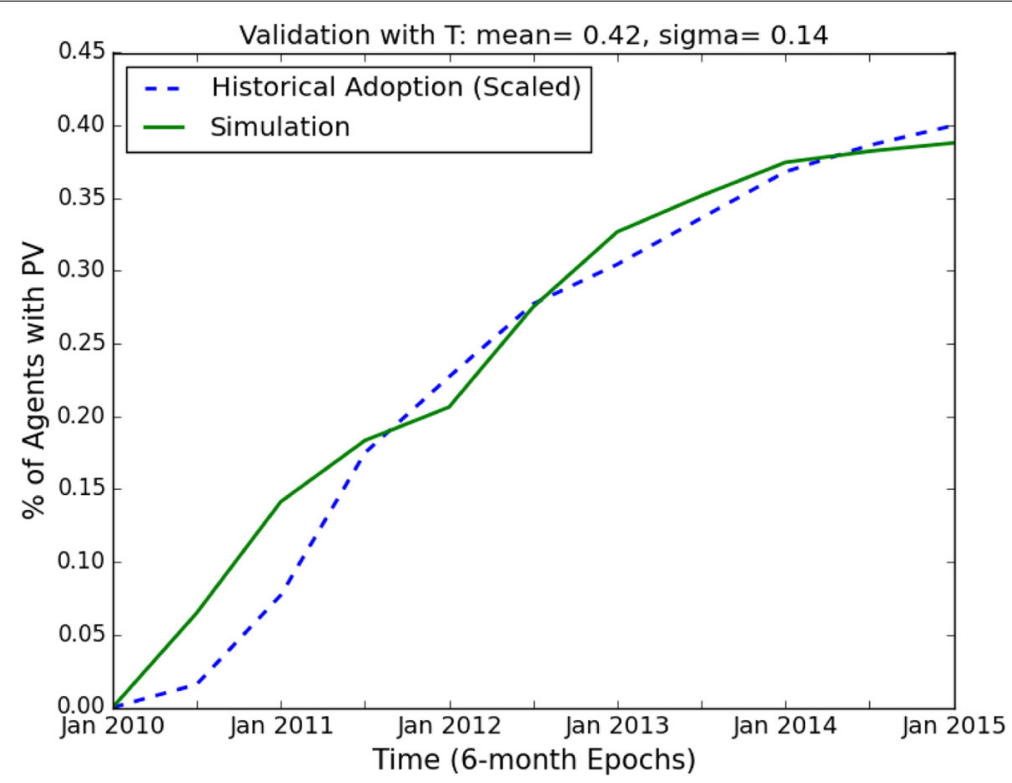

Fig. 8 Scaled Historical Adoption, Ontario

- Reduced price for battery storage (compared to the base case)

Figures 9 shows the changes in the model parameters over time that result from these policy prescriptions.

\section{PV adoption}

PV adoption results for each simulation scenario are shown in Figs. 1011 and $12^{9}$. This adoption comprises both FiT and net metering contracts. The bars show the $95 \%$ confidence interval; large intervals show the difficulty of making specific predictions. For example, it appears that both decreasing PV prices and increased ToU rates increase adoption, but their combination performs worse than each individually. We attribute this

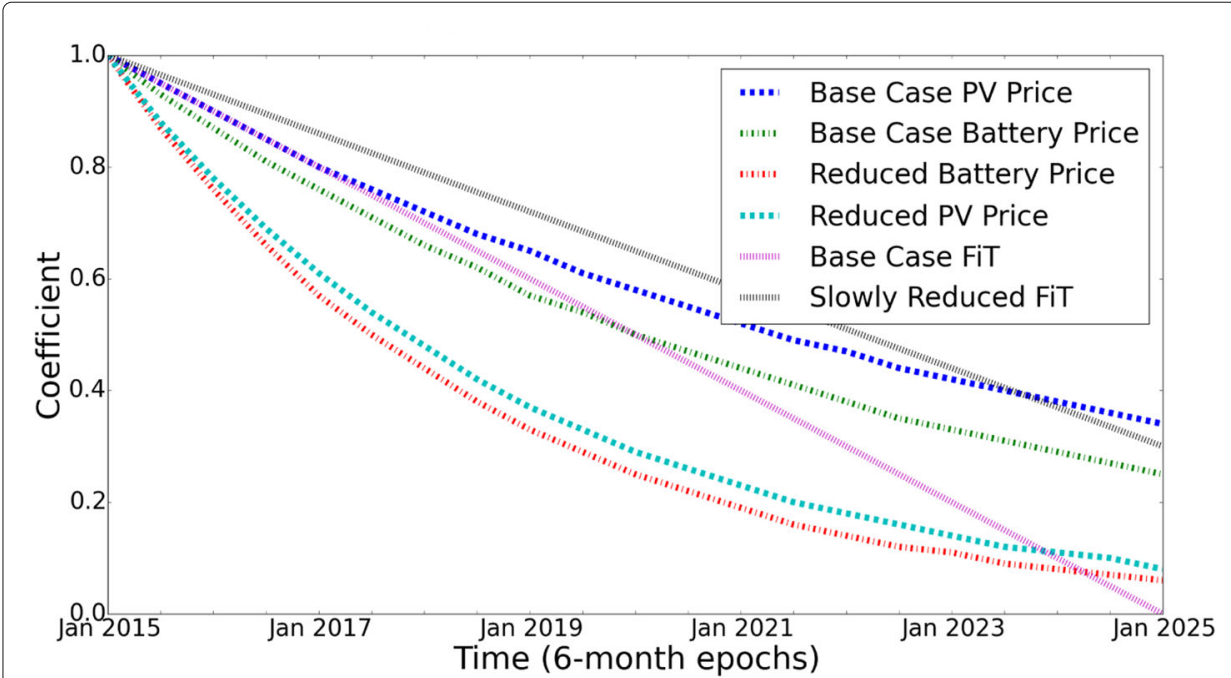

Fig. 9 Coefficient in Base Case and Alternative Scenarios, Ontario 


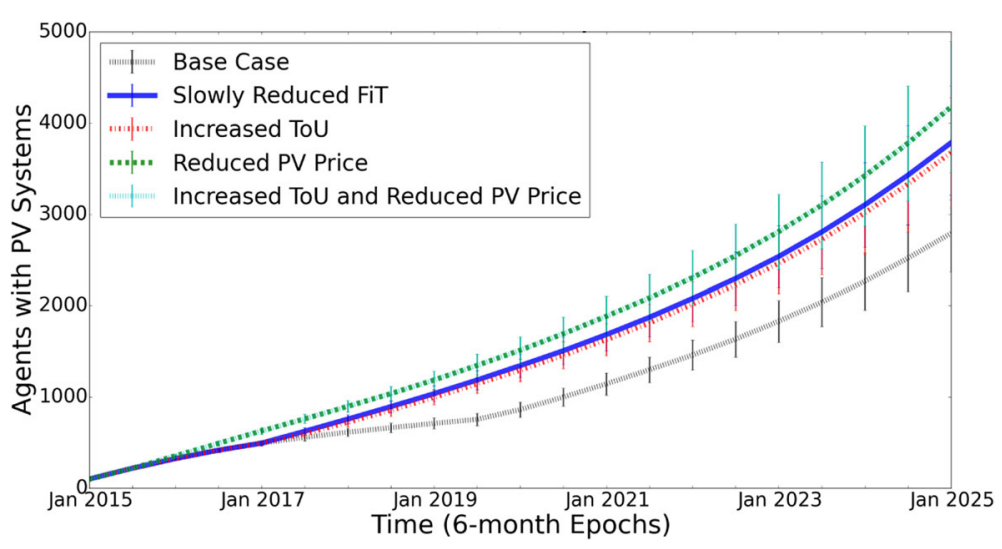

Fig. 10 Total PV Adoption, Ontario

to experimental 'noise'. Nonetheless, the results still inform the policy selection process, given the adoption trends.

Recall that there are approximately 26,000 agents, so there is about $15 \%$ penetration at the end of the simulation period in all cases. This growth is driven primarily by the expected drop in PV prices, with no additional policy stimulus. Nevertheless, there is a significant improvement possible due to the use of appropriate policies. In particular, a reduction in PV prices, over and above market price, due to purchase tax credits for example, can significantly improve PV adoption. It is also clear that increased grid prices tend to suppress FiT contracts and incentivize net metering contracts.

\section{Battery adoption}

We show the adoption of batteries in different scenarios in Figs. 13 and 14. Note that battery adoption is influenced by the attractiveness of solar PV adoption (without a PV system being purchased, there is no need for a battery). The base case has the lowest battery adoption. While reducing battery prices improves battery adoption, higher electricity prices can also motivate battery adoption. The best case is sue to a reduction in both PV and battery prices simultaneously; again, something that can be accomplished using purchase tax credits.

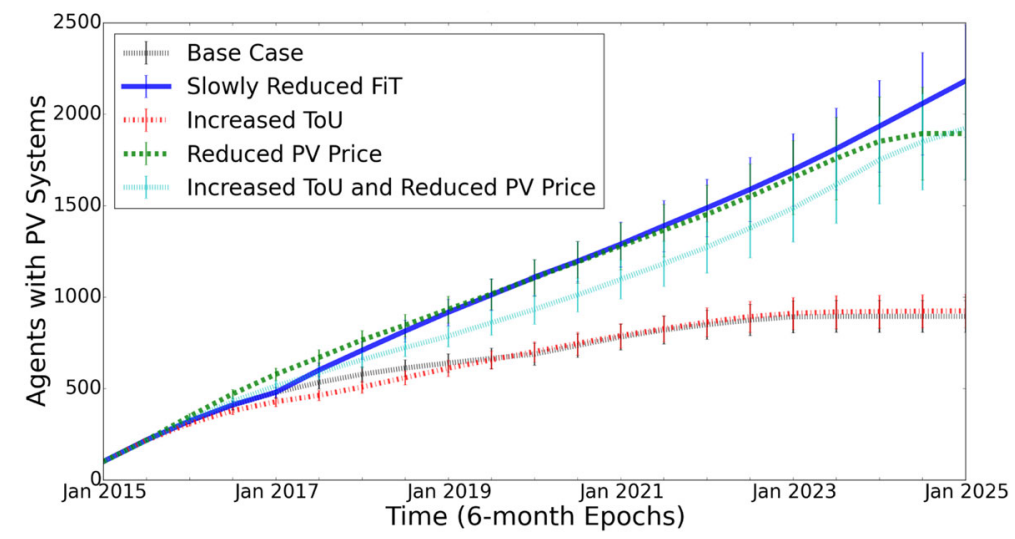

Fig. 11 FiT Contracts, Ontario 


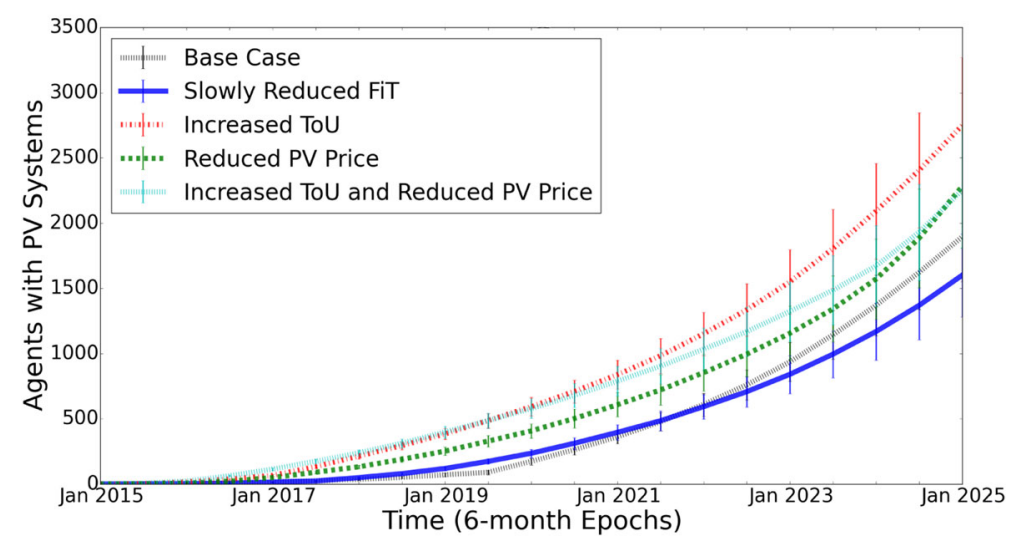

Fig. 12 Net Metering Contracts, Ontario

\section{Germany case study}

In this section, we use ABMs to study PV-battery system adoption in Germany. In the interests of space, we only highlight the differences between this study and the Ontario study. Note that, unlike Ontario, homeowners in Germany can only sign FiT contracts, but not net metering contracts. Therefore, if the FiT price is lower than the price of grid electricity, an agent sells its excess electricity to the grid. This is similar in principle to net metering. However, if the FiT price is higher than the price of grid electricity, and agent sells all of its PV generation to the grid at that price and uses electricity from the grid instead.

\section{Data}

We obtain German electricity prices from public sources: (Eurostat 2016), (Statista 2017). PV-battery system prices are publicly available for Germany and are shown in Table 1.

Lacking load traces from measurements, we use a load simulator (Pflugradt 2017) to generate hourly load traces for households with different numbers of residents. We use HOMER (HOMER 2016) to estimate solar PV generation, based on radiation measured by solar stations in Germany. To determine agent parameters, we conducted a survey, similar to the Ontario survey, also using CrowdFlower (Crowdflower Inc. 2017), but only

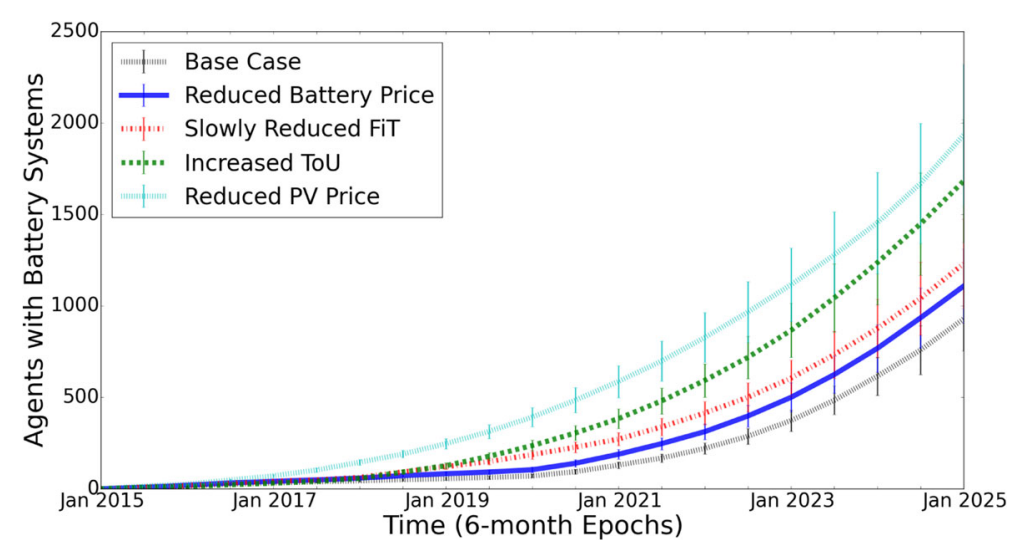

Fig. 13 Battery adoption in different scenarios with single variables changed from base case, Ontario 


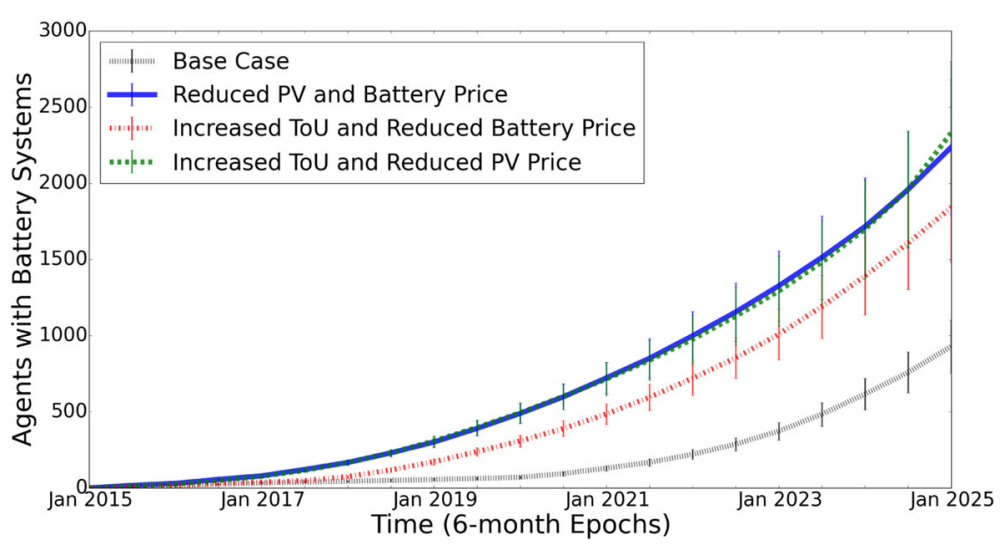

Fig. 14 Battery adoption in different scenarios with multiple variables changed from base case, Ontario

open to to German residents. Specifically, we asked which solar and solar/storage systems a respondent would consider purchasing, and how much the respondents care about factors such as system cost. An example question is shown in Fig. $15^{10}$. As with the Ontario survey, we added test questions to check if respondents were paying attention to the questions. We had 520 survey responses from Germany using CrowdFlower, out of which 150 were judged to be valid because they answered our attention test question correctly.

\section{Feature selection and logistic regression}

As in the Ontario case study, we use ridge regression and 10-fold cross validation to find a decision function for feature selection. We find that the payback period, budget of the respondent, greenness, and the stated social effect have a significant impact of PV purchase decisions (Fig. 16). Based on the agent decision model and typical behaviours, we

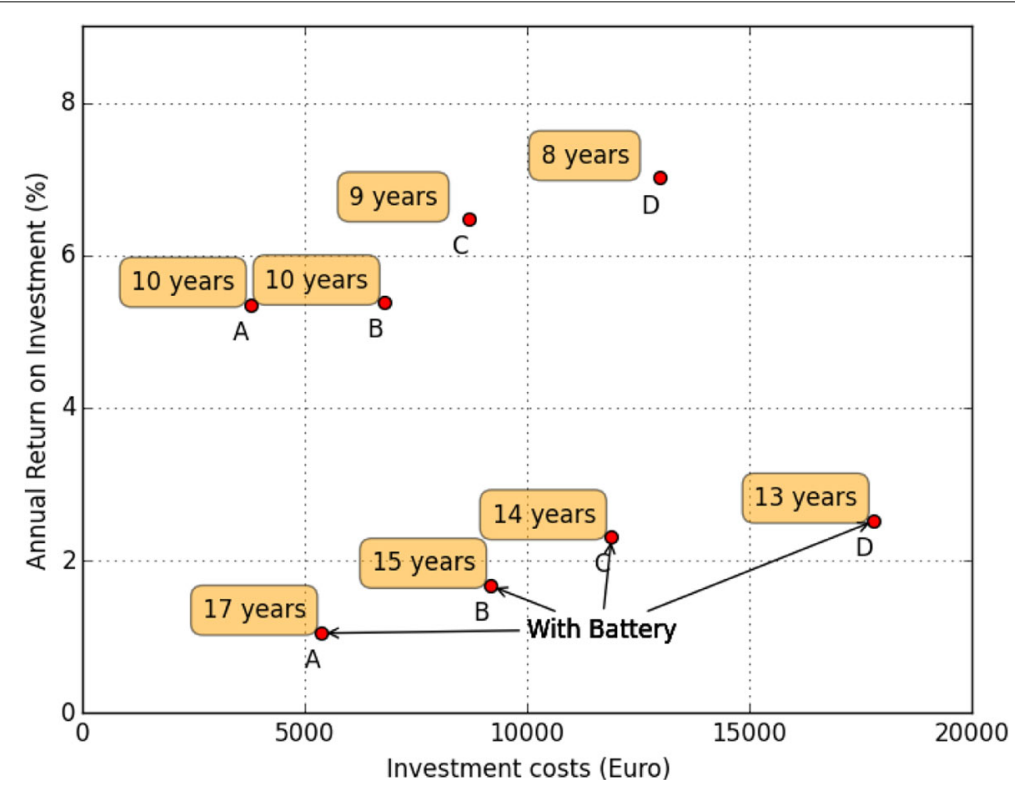

Fig. 15 Sample Survey Question (Germany): Which system(s) would you buy? 


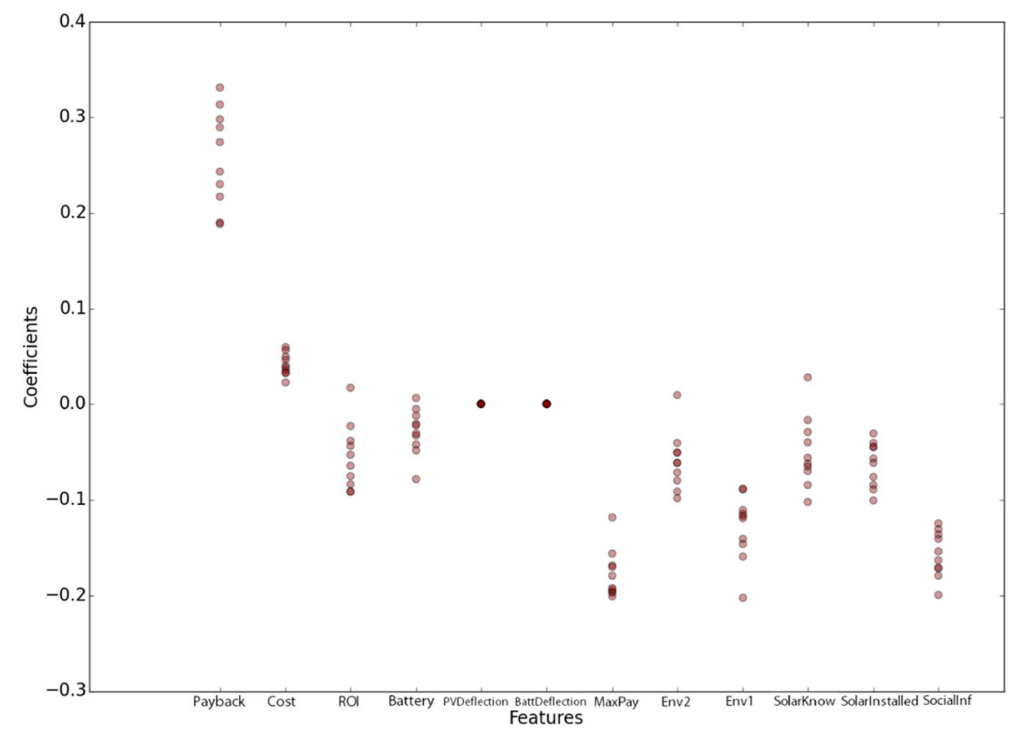

Fig. 16 Feature Selection using Ridge Regression (Germany)

found the decision function to be well-modeled by the logistic regression model parameters in Table 4. Agent purchase decisions are made using the same algorithm as in Ontario (“Agent behaviour" section).

\section{Validation}

Similar to the Ontario study, we used simulations to compare predicted adoption with historical adoption between 2004 and 2014 (BSW-Solar 2015), because the German FiT program started in August 2004. With the assumption that only households purchased FiT contracts, the historical adoption was scaled to the agent population size, i.e., 13,250 agents. Environment variables such as FiT, PV prices, battery prices, and price of electricity were replicated based on historical data during the simulated years (BDEW 2015b; Wirth and Schneider 2015; BDEW 2015a).

We find the closest fit and lowest error with a social threshold $T$ distribution of $\mu=0.26$ and $\sigma=0.18$. Figure 17 shows the errors for different values of $\mu$ and $\sigma$. The Fig. 18 also shows the simulated adoption from 2004 to 2014, compared to the historical adoption during this period, showing a reasonably good fit. Therefore, in scenario simulations, we assign agents a social threshold $T_{i}$ from a normal distribution with $\mu=0.26$ and $\sigma=0.18$, truncated at 0 .

Table 4 Logistic Regression Result (Germany)

\begin{tabular}{lllll}
\hline Variable & Coefficient & Standard error & $z$ & $P>|z|$ \\
\hline Intercept & 0.9492 & 0.203 & 4.673 & 0.000 \\
Payback & 0.0734 & 0.011 & 6.731 & 0.000 \\
PV Budget & -0.0933 & 0.019 & -4.961 & 0.000 \\
Greenness & -0.1417 & 0.037 & -3.810 & 0.000 \\
Social Effect & -0.1374 & 0.033 & -4.151 & 0.000 \\
\hline
\end{tabular}




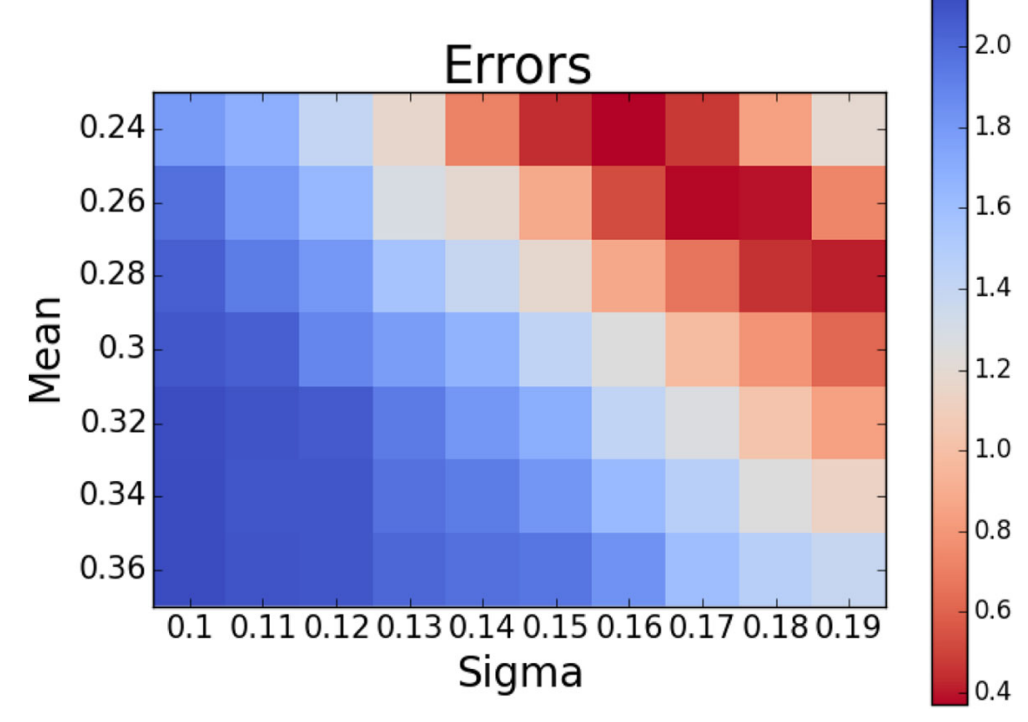

Fig. 17 RMSE for different values of the parameters of the social threshold distribution, Germany

\section{Simulation results}

\section{Policy parameters}

We studied the following policy scenarios (these mimic the Ontario scenarios, with minor differences):

- Base Case: This is the scenario where current market trends continue. We vary the environment variables based on best-fit extrapolations (Pescia et al. 2015;

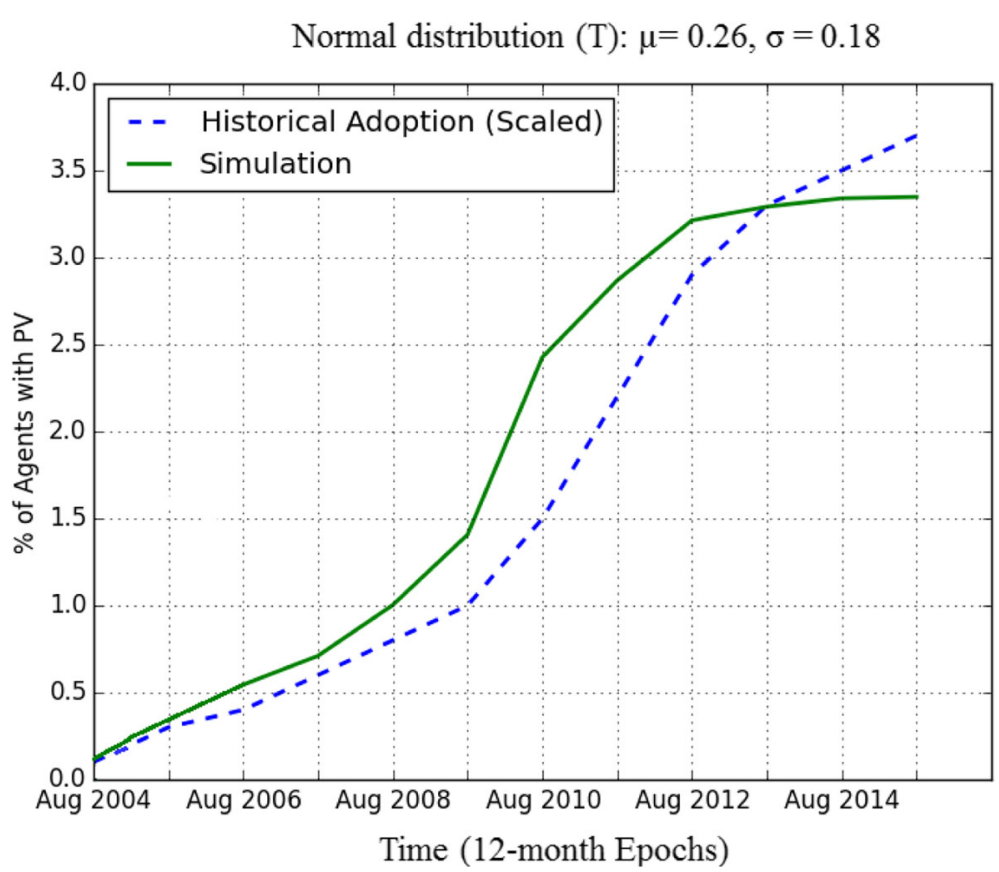

Fig. 18 Scaled Historical Adoption, Germany 


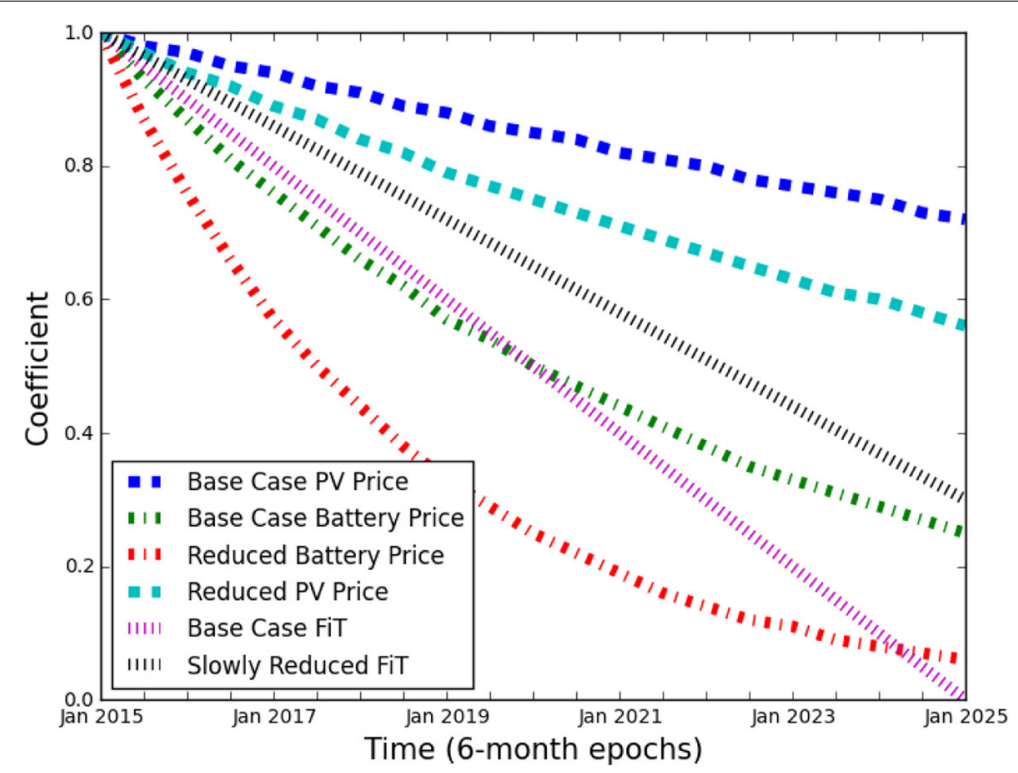

Fig. 19 Coefficients for PV Price, Battery Price, and FiT in Germany

Energiewende 2015; AECOM 2015). As with Ontario, we reduce the FiT at a linear rate towards a price of $€ 0.0 / \mathrm{kWh}$ in 2025

- Reduced price of PV systems (compared to the base case)

- Increased electricity (kWh) price by a ratio of 2.4:1 (compared 1.6:1 to the base case)

- Reduced battery price (compared to the base case)

Figure 19 shows the changes in the model coefficients over time that result from these policy prescriptions.

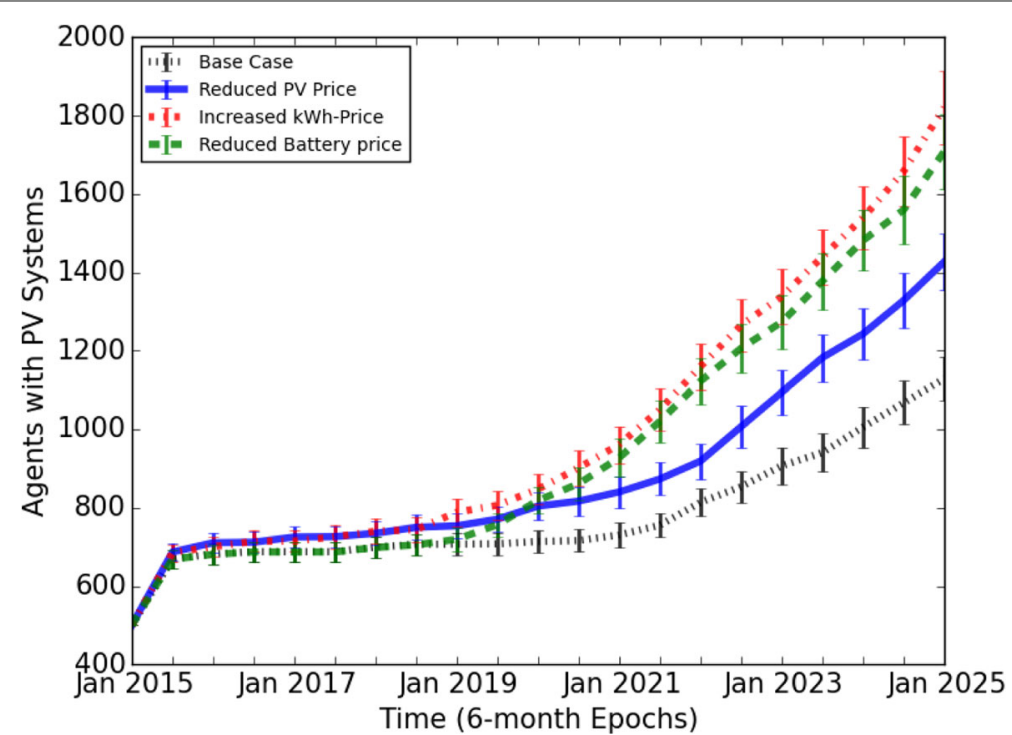

Fig. 20 PV Adoption in Different Scenarios with Single Variables Changed from Base Case, Germany 


\section{PV adoption}

For PV adoption, the base case in Figs. 20 and 21 shows adoption rates plateauing after an initial small increase, then increasing only after about six years, when PV prices are sufficiently low and electricity prices are expected to be high. Indeed, PV adoption in Germany has been quite slow for the last few years, which is reflected in this analysis. However, our study shows that in a few years, this combined change in the environment results in the availability of PV systems with shorter payback periods, providing an economically viable alternative to grid electricity, which will spur the adoption of PV systems.

The highest rate of adoption - $28 \%$ - is when electricity price is increased and PV prices are simultaneously reduced. In addition, we find that increasing the price of electricity has the most significant impact of PV adoption. Based on our findings, we expect the ownership of PV-battery systems to continue to increase in the long term, particularly with self-consumption of PV electricity becoming a more attractive option for households.

\section{Battery adoption}

Figures 23 and 22 shows the battery adoption in several scenarios. In the base case, there is a significant increase in battery adoption only after five years of very low ownership. This is because, it is only by 2020 that the price of electricity is sufficiently high for agents to benefit from purchasing batteries for electricity storage. This was also observed by Kaschub et al in recent work (Kaschub et al. 2016). In addition, the scenario that combines reduction in PV-battery system prices and increased electricity price results has highest battery adoption among all scenarios considered.

\section{Comparison between Ontario and Germany case studies}

We now compare the results from both jurisdictions. While these results are suggestive, we caution that they are each dependent on numerous modeling assumptions. We therefore have made an attempt to only draw conclusions that appear to be robust to modeling errors. First, in comparing the penetration of solar PV systems in Ontario and Germany,

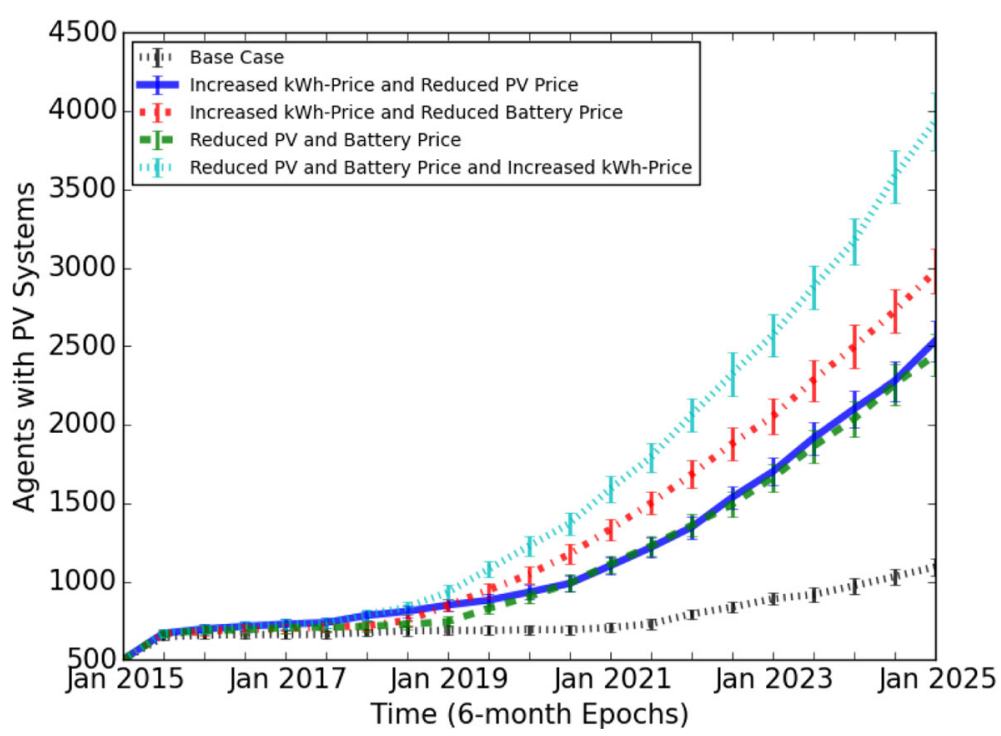

Fig. 21 PV Adoption in Different Scenarios with Multiple Variables Changed from Base Case, Germany 


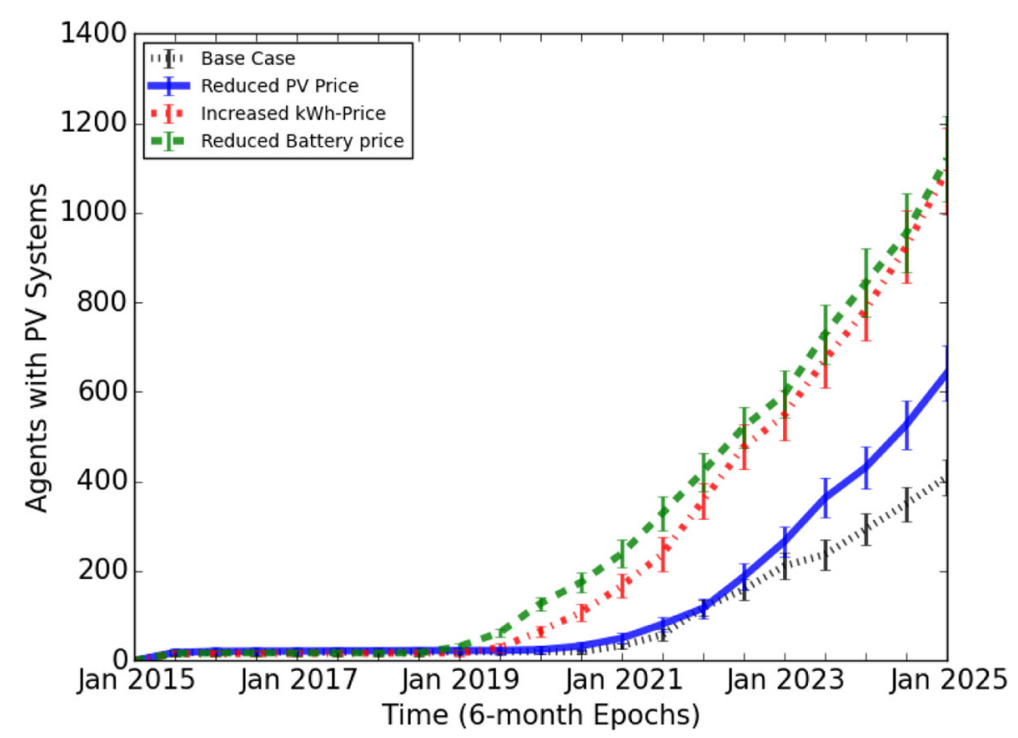

Fig. 22 Battery Adoption in Different Scenarios with Single Variables Changed from Base Case, Germany

we must keep in mind that they are at already at different stages of PV adoption. Specifically, in January 2015 the household penetration of solar PV systems in Ontario was about $0.4 \%$ while that in Germany was over $3.5 \%$, about an order of magnitude greater. This difference in the phase of penetration results in the differneces in the adoption decision functions shown in Tables 3 and 4. Note that in these tables, while the payback and stated budget are common to both PV-battery system adoption functions, greenness and social effect are also significant in the decision of German respondents to purchase PV-battery systems, unlike Ontario respondents. Thus, taking the physical environment into consideration when buying solar PV systems seems to correspond to the emphasis on renewable energy in German policies such as the Energiewende (Pescia et al. 2015).

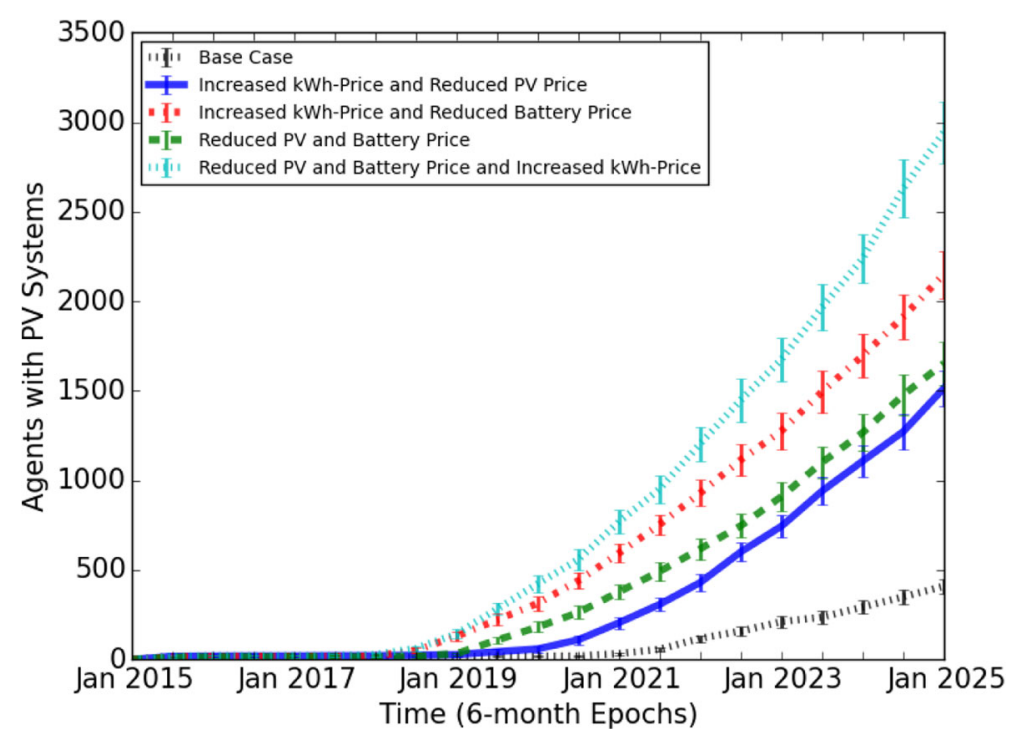

Fig. 23 Battery Adoption in Different Scenarios with Multiple Variables Changed from Base Case, Germany 
Second, our simulation results indicate that in the Ontario base case, we can expect a steady increase over the entire time period (Fig. 10). In contrast, in the German base case, we predict a plateau in adoption for the first six years, followed by an increase; the plateau phase ends around 2019 when PV prices are sufficiently low and electricity prices are expected to be high (Fig. 21). We believe that one of the policies suggested in this paper would reduce the duration of the plateau. For example, a greater rate of increase in electricity prices would cause the plateau to end about a year sooner.

Finally, of the set of polices that we studied, reducing the price of PV systems appears to result in the highest increase adoption of PV systems in Ontario, while increasing the price of electricity in Germany results in the highest level of adoption. We attribute this difference to the fact that the price of electricity in Germany is relatively higher, so that further increasing the electricity price may be the best way to further improving adoption there.

\section{Conclusions}

We present an ABM-based approach to model and forecast PV-battery adoption and usage, with case studies in both Ontario and Germany. Different populations adopt PVbattery systems differently, based on local economic variables as well as non-economic factors such as self-perceived 'greenness.' Thus, it is important to understand the population and evaluating existing adoption dynamics before suggesting new policy prescriptions. We have been diligent in selecting appropriate data sources to model each jurisdiction. Moreover, ABM parameters, such as the purchase decision function, are determined by conducting surveys in the target populations, hence the expectation to accurately reflect biases in the population. With this ABM-based approach, the adoption and usage of PV-battery systems can be estimated before policies are actually implemented.

We used historical adoption patterns to both choose a free model variable (the adoption threshold) as well as to validate the accuracy of our model. With the proper selection of ABM parameters, we find that our models are able to model historical adoption to a reasonable degree of accuracy.

We use our ABMs to simulate the impact of a set of different policy prescriptions in both jurisdictions. While we caution that our models are only approximate, it appears that in Germany, 'greenness' (i.e., concern for the environment) plays a role in the decision to purchase a PV system, unlike Ontario. Based on this difference, as well as differences in the number of existing solar installations, grid electricity price, and cost of PV systems in both jurisdictions, we find that different policies bring about the most significant increase in adoption. Specifically, reducing PV prices appear to have the most significant impact on adoption in Ontario while increasing the price of electricity would appear to have the most significant impact in Germany.

We also found that policy prescriptions can indeed play a significant role in the adoption of battery systems in both jurisdictions. Without any intervention, there is insignificant adoption of battery systems in both jurisdictions until 2021 or 2022. However, by providing tax credits or discounts for battery systems, or by increasing the price of grid electricity, these systems could be made more desirable.

To conclude, we believe that ABMs, when properly calibrated, are a useful and pragmatic approach to evaluate the impact of potential policy prescriptions in different 
jurisdictions. We have used this approach to compare the impact of impact of different policies in both Ontario and Germany, finding specific policies that can be used to significant improve adoption in both jurisdictions.

\section{Endnotes}

${ }^{1}$ http://unfccc.int/paris_agreement/items/9485.php

${ }^{2}$ This paper summarizes and extends our prior work in using ABMs to forecast PV and storage adoption in Ontario (Adepetu and Keshav 2016b) and Germany (Alyousef et al. 2017).

${ }^{3}$ https://en.wikipedia.org/wiki/German_Renewable_Energy_Sources_Act

${ }^{4}$ Due to confidentiality requirements, these sources cannot be named

${ }^{5}$ Prices listed in this study are in Canadian Dollars, unless stated otherwise

${ }^{6}$ The entire survey can be found as Appendix A.2 of Reference (Adepetu 2016a).

${ }^{7}$ Ancillary charges, such as delivery and clean energy charges, constitute a significant part of the electricity bill in Canada. It is unclear how these charges are estimated. Consequently, we excluded these charges from our electricity bill calculations.

${ }^{8}$ Ridge regression allows feature selection even in the presence of correlated features.

${ }^{9}$ Please note that in order to emphasize the difference between various policies, we have chosen to use different $\mathrm{Y}$-axis scales in our results.

${ }^{10}$ This survey is a German translation of the one that can be found in Appendix A.2 of Reference (Adepetu 2016a).

Funding

This work was supported by Cisco Systems Canada and the Canadian Natural Sciences and Engineering Research Council under a Cooperative Research and Development grant and has received funding from the European Union's Horizon 2020 research and innovation programme under grant agreement No. 713864 (ELECTRIFIC).

\section{Availability of data and materials}

Please contact the authors to obtain anonymized survey data and source code for the ABM models.

\section{Authors' contributions}

AA and AA were responsible for conducting the survey, carrying out simulations, and reporting on the results. They also wrote the first draft of the paper. SK and HdM provided research direction, supervision, and funding. They also helped to write the final version of the paper. All authors read and approved the final manuscript.

Competing interests

We do not have competing interests in the research presented in this paper.

\section{Publisher's Note}

Springer Nature remains neutral with regard to jurisdictional claims in published maps and institutional affiliations.

\section{Author details}

${ }^{1}$ University of Waterloo, 200 University Avenue West, Waterloo, Canada. ${ }^{2}$ University of Passau, Innstraße 43, 94032 Passau, Germany.

Received: 23 January 2018 Accepted: 23 March 2018

Published online: 26 July 2018

\section{References}

Adepetu A (2016a) Agent-Based Modeling Framework for Energy Policies. PhD thesis, University of Waterloo. http://hdl. handle.net/10012/10614, Accessed Jan 2018

Adepetu A, Keshav S (2016b) Understanding Solar PV and Battery Adoption in Ontario: An Agent-based Approach. In: Proceedings of the Seventh International Conference on Future Energy Systems. e-Energy '16. ACM, New York. pp 5-1512. https://doi.org/10.1145/2934328.2934333.http://doi.acm.org/10.1145/2934328.2934333

AECOM (2015) AECOM Australia: Energy Storage Study. Accessed on 12 Sept 2017. https://arena.gov.au/assets/2015/07/ AECOM-Energy-Storage-Study.pdf

Alyousef A, Adepetu A, de Meer H (2017) Analysis and model-based predictions of solar PV and battery adoption in Germany: an agent-based approach. Comput Sci-Res Dev 32(1-2):211-223

Bass FM (2004) Comments on "a new product growth for model consumer durables the bass model". Management science 50(12_supplement):1833-1840 
BDEW (2015a) BDEW: German Household Electricity Costs Fall 1\% in 2015 - 3,500 kWh/year for EUR 84.02/month or 28.81 ct/kWh Published on April 9, 2015 in Electricity and Grid. Accessed on 12 Sept 2017. http://www.germanenergyblog. de/?p=18391

BDEW (2015b) Statistische Zahlen der deutschen Solarstrombranche (Photovoltaik). Accesses on 12 Sept 2017. https:// www.solarwirtschaft.de/fileadmin/media/pdf/2016_3_BSW_Solar_Faktenblatt_Photovoltaik.pdf

Blair N, Dobos AP, Freeman J, Neises T, Wagner M, Ferguson T, Gilman P, Janzou S (2014) System advisor model, sam 2014.1. 14: General description. Technical report, National Renewable Energy Laboratory (NREL), Golden, CO

BNetzA (2015a) Bundesnetzagentur: Entwicklung des deutschen PV-Marktes, "PV-Meldedaten Jan. - Feb. 2015". https:// www.solarwirtschaft.de/fileadmin/media/pdf/BNetzA-Daten_Jan_2015_kurz.pdf, Accessed Jan 2018

BNetzA (2015b) Photovoltaikanlagen: Datenmeldungen sowie EEG-Verguetungssaetze [Monthly reported new installations of PV systems and current feed-in tariffs of the German Renewable Energy Act]. Accessed on 12 Sept 2017. https://www.bundesnetzagentur.de/DE/Sachgebiete/ElektrizitaetundGas/Unternehmen_Institutionen/ ErneuerbareEnergien/Photovoltaik/DatenMeldgn_EEG-VergSaetze/DatenMeldgn_EEG-VergSaetze_node.html

BSW-Solar (2015) Entwicklung des deutschen PV-Marktes. Accessed on 12 Sept 2017. https://www.solarwirtschaft.de/ fileadmin/media/pdf/bnetza_0214_kurz.pdf

Crowdflower Inc. (2017) Crowdflower: Make Your Data Useful. Accessed on 12 Sept 2017. http://www.crowdflower.com/

Energiewende A (2015) Current and future cost of photovoltaics; long-term scenarios for market development, system prices and Icoe of utilityscale pv-systems. Report by Fraunhofer Institute for Solar Energy Systems on behalf of Agora Energiewende. Accessed: 12 Sept 2017

Eurostat (2016) Energy price statistics. Accessed on 12 Sept 2017. http://ec.europa.eu/eurostat/statistics-explained/index. php/Energy_price_statistics

Feldman D, Barbose G, Margolis R, James T, Weaver S, Darghouth N, Fu R, Davidson C, Booth S, Wiser R, et al (2014) Photovoltaic system pricing trends. US Department of Energy. Available online as https://www.nrel.gov/docs/ fy140sti/62558.pdf Acessed June 2018

Ghiassi-Farrokhfal Y, Keshav S, Rosenberg C (2015) Toward a realistic performance analysis of storage systems in smart grids. IEEE Trans Smart Grid 6(1):402-410

Granovetter M (1978) Threshold Models of Collective Behavior. Am J Sociol 83(6):1420-1443

HOMER (2016) The HOMER Microgrid Software. http://www.homerenergy.com/software.html, Accessed Jan 2018

Hoerl AE, Kennard RW (1970) Ridge Regression: Biased Estimation for Nonorthogonal Problems. Technometrics 12(1):55-67

lachini V, Borghesi A, Milano M (2015) Agent based simulation of incentive mechanisms on photovoltaic adoption. In: A** IA 2015, Advances in Artificial Intelligence. Springer. pp 136-148

IESO (2015a) microFIT Program. Accessed on 12 Sept 2017. http://microfit.powerauthority.on.ca/solar-photovoltaic-pv

IESO (2015b) Progress Report on Contracted Electricity Supply. Accessed on 12 Sept 2017. http://www.ieso.ca/ Documents/Supply/Progress-Report-Contracted-Supply-Q12015.pdf

IESO (2016) Progress Report on Contracted Electricity Supply. Accessed on 12 Sept 2017. http://www.ieso.ca/ Documents/Supply/Progress-Report-Contracted-Supply-Q12016.pdf

Kaschub T, Jochem P, Fichtner W (2016) Solar energy storage in german households: profitability, load changes and flexibility. Energy Policy 98:520-532

Kazhamiaka F, Jochem P, Keshav S, Rosenberg C (2017) On the influence of jurisdiction on the profitability of residential photovoltaic-storage systems: A multi-national case study. Energy Pol 109(Supplement C):428-440. https://doi.org/ 10.1016/j.enpol.2017.07.019

Kulviwat S, Bruner GC, Al-Shuridah O (2009) The role of social influence on adoption of high tech innovations: The moderating effect of public/private consumption. J Bus Res 62(7):706-712

Macal CM, North MJ (2010) Tutorial on agent-based modelling and simulation. J Simul 4(3):151-162

Murakami T (2014) Agent-based simulations of the influence of social policy and neighboring communication on the adoption of grid-connected photovoltaics. Energy Convers Manag 80:158-164

Nikolic l, Ghorbani A (2011) A method for developing agent-based models of socio-technical systems. In: Networking, Sensing and Control (ICNSC), 2011 IEEE International Conference On. IEEE, New York. pp 44-49

Ontario Energy Board (2015a) Electricity Prices. Accessed on 12 Sept 2017. http://www.ontarioenergyboard.ca/OEB/ Consumers/Electricity/Electricity+Prices

Ontario Energy Board (2015b) Historical Electricity Prices. Accessed on 09 Nov 2015. http://www.ontarioenergyboard.ca/ $\mathrm{OEB} /$ Consumers/Electricity/Electricity+Prices/Historical+Electricity+Prices

Palmer J, Sorda G, Madlener R (2015) Modeling the diffusion of residential photovoltaic systems in italy: An agent-based simulation. Technol Forecast Soc Chang 99:106-131

Parkinson G (2015) Solar PV costs to fall another 25 percent in three years. Accessed on 12 Sept 2017. http:// reneweconomy.com.au/2015/solar-pv-costs-to-fall-another-25-per-cent-in-three-years-32854

Pescia D, Graichen P, Jacobs D (2015) Understanding the energiewende. FAQ on the Ongoing Transition of the German Power System. Available online as https://www.agora-energiewende.de/fileadmin2/Projekte/2015/ Understanding_the_EW/Agora_Understanding_the_Energiewende.pdf. Accessed June 2018

Pflugradt N (2017) Load Profile Generator. http://www.loadprofilegenerator.de

Rai V, Robinson SA (2015) Agent-based modeling of energy technology adoption: Empirical integration of social, behavioral, economic, and environmental factors. Environ Model Softw 70:163-177

Robinson SA, Stringer M, Rai V, Tondon A (2013) GIS-integrated agent-based model of residential solar pv diffusion. In: 32nd USAEE/IAEE North American Conference. pp 28-31

Shahan Z (2015) Tesla Powerwall \& Powerpacks Per-kWh Lifetime Prices vs Aquion Energy, Eos Energy, \& Imergy. Accessed on 12 Sept 2017. http://cleantechnica.com/2015/05/09/tesla-powerwall-powerblocks-per-kwh-lifetimeprices-vs-aquion-energy-eos-energy-imergy/

Statista (2017) Statista - Das Statistik-Portal. http://www.statista.com/, Accessed Jan 2018

Statistics Canada (2011) Private households by structural type of dwelling, by province and territory (2011 Census)(New Brunswick, Quebec, Ontario). Accessed on 15 Mar 2018. http://www.statcan.gc.ca/tables-tableaux/sum-som/l01/ cst01/famil55b-eng.htm 
SunSmart Solar (2016) Ontario Feed-In Tariff, MicroFIT and FIT Program Installation. Accessed on 12 Sept 2017. http:// www.sunsmart.solar/ontario-microfit/

Van Dam KH, Nikolic I, Lukszo Z (2012) Agent-based Modeling of Socio-technical Systems. vol. 9. Springer Science and Business Media

Wang D, Ren C, Sivasubramaniam A, Urgaonkar B, Fathy H (2012) Energy storage in datacenters: What, where, and how much?. SIGMETRICS Perform Eval Rev 40(1):187-198. https://doi.org/10.1145/2318857.2254780

Wirth H, Schneider K (2015) Aktuelle fakten zur photovoltaik in deutschland. Fraunhofer ISE. Available online at https:// www.ise.fraunhofer.de/content/dam/ise/de/documents/publications/studies/aktuelle-fakten-zur-photovoltaik-indeutschland.pdf Accessed June 2018

Zhao J, Mazhari E, Celik N, Son Y-J (2011) Hybrid agent-based simulation for policy evaluation of solar power generation systems. Simul Model Pract Theory 19(10):2189-2205

Zhang H, Vorobeychik Y, Letchford J, Lakkaraju K (2014) Predicting rooftop solar adoption using agent-based modeling. In: 2014 AAAl Fall Symposium Series

Zhang H, Vorobeychik Y, Letchford J, Lakkaraju K (2015) Data-driven agent-based modeling, with application to rooftop solar adoption. In: Proceedings of the 2015 International Conference on Autonomous Agents and Multiagent Systems. pp 513-521. International Foundation for Autonomous Agents and Multiagent Systems

Submit your manuscript to a SpringerOpen ${ }^{\circ}$ journal and benefit from:

- Convenient online submission

- Rigorous peer review

- Immediate publication on acceptance

- Open access: articles freely available online

- High visibility within the field

- Retaining the copyright to your article

Submit your next manuscript at $\boldsymbol{\wedge}$ springeropen.com 